\title{
Reversine induces cell cycle arrest and apoptosis via upregulation of the Fas and DR5 signaling pathways in human colorectal cancer cells
}

\author{
YOUNG-LAN PARK*, SANG-YOON HA*, SUN-YOUNG PARK, JUNG-HO CHOI, MIN-WOO JUNG, \\ DAE-SEONG MYUNG, HYUN-SOO KIM and YOUNG-EUN JOO
}

Department of Internal Medicine, Chonnam National University Medical School, Gwangju 501-757, Republic of Korea

Received November 5, 2018; Accepted February 22, 2019

DOI: $10.3892 /$ ijo.2019.4746

\begin{abstract}
Reversine, a 2,6-diamino-substituted purine analogue, has been reported to be effective in tumor suppression via induction of cell growth arrest and apoptosis of cancer cells. However, it remains unclear whether reversine exerts anticancer effects on human colorectal cancer cells. In the present study, in vitro experiments were conducted to investigate the anticancer properties of reversine in human colorectal cancer cells. The effect of reversine on human colorectal cancer cell lines, SW480 and HCT-116, was examined using a WST-1 cell viability assay, fluorescence microscopy, flow cytometry, DNA fragmentation, small interfering RNA (siRNA) and western blotting. Reversine treatment demonstrated cytotoxic activity in human colorectal cancer cells. It also induced apoptosis by activating poly(ADP-ribose) polymerase, caspase-3, -7 and -8, and increasing the levels of the pro-apoptotic protein second mitochondria-derived activator of caspase/direct inhibitor of apoptosis-binding protein with low pI. The pan-caspase inhibitor Z-VAD-FMK attenuated these reversine-induced apoptotic effects on human colorectal cancer cells. Additionally, reversine treatment induced cell cycle arrest in the subG1 and G2/M phases via increase in levels of p21, p27 and p57, and decrease in cyclin D1 levels. The expression of Fas and death receptor 5 (DR5) signaling proteins in SW480 and HCT116 cells was upregulated by reversine treatment. Reversine-induced apoptosis and cell cycle arrest were suppressed by inhibition of Fas and DR5 expression via siRNA. In conclusion, Reversine treatment suppressed tumor
\end{abstract}

Correspondence to: Professor Young-Eun Joo, Department of Internal Medicine, Chonnam National University Medical School, 8 Hak-Dong, Gwangju 501-757, Republic of Korea

E-mail: yejoo@chonnam.ac.kr

*Contributed equally

Key words: reversine, colorectal cancer cells, apoptosis, Fas, death receptor 5 progression by the inhibition of cell proliferation, induction of cell cycle arrest and induction of apoptosis via upregulation of the Fas and DR5 signaling pathways in human colorectal cancer cells. The present study indicated that reversine may be used as a novel anticancer agent in human colorectal cancer.

\section{Introduction}

Colorectal cancer is one of the most common causes of cancer-associated morbidity and mortality globally $(1,2)$. Despite advances in treatment, including surgery, chemotherapy and radiotherapy, the prognosis of advanced colorectal cancer remains poor $(1,2)$. Therefore, development of an efficient and safe anticancer agent is required to improve the prognosis of patients with advanced colorectal cancer.

Reversine, a 2,6-diamino-substituted purine analogue, was initially used as a dedifferentiation agent that induces lineage reversal of $\mathrm{C} 2 \mathrm{C} 12$ murine myoblasts cells to become multipotent progenitor cells, which can subsequently redifferentiate into osteoblasts, adipocytes, neural lineage cells and cardiomyocytes under lineage-specific inducing conditions (3-6). The activity of reversine as a dedifferentiation agent may be applicable to cancer biology and therapy.

The Aurora kinases, a family of mitotic serine/threonine kinases, serve a critical role in regulating cell-cycle progression, and aberrant expression of these kinases has been reported in a broad range of human cancer types, including breast, ovarian and gastric cancer (7-9). Numerous studies demonstrated that reversine possesses anticancer properties, causing cell growth arrest, cell cycle arrest, apoptosis, polyploidy and autophagy via the inhibition of Aurora kinases in various human cancer cell lines, including breast, thyroid, kidney, cervix, lung and colon cancer (10-23). Additionally, reversine inhibits tumor growth, as observed from xenograft mice model experiments $(22,23)$. The results indicated that reversine may be used as an anticancer agent.

However, it remains unclear whether reversine exerts an anticancer effect in human colorectal cancer cells. The aim of the present study was to investigate the impact of reversine on tumor cell behavior and its association with intracellular signaling pathways in human colorectal cancer cells. 


\section{Materials and methods}

Cell culture and materials. Human colorectal carcinoma cell lines SW480 (ATCC ${ }^{\circledR}$ CCL-228 $\left.{ }^{\mathrm{TM}}\right)$ and HCT116 $\left(\mathrm{ATCC}^{\circledR}\right.$ CCL-247 ${ }^{\mathrm{TM}}$ ) were purchased from the American Type Culture Collection (Manassas, VA, USA). The SW480 cells were cultured in Dulbecco's modified Eagle's medium (Gibco; Thermo Fisher Scientific, Inc., Waltham, MA, USA). The HCT116 cells were cultured in McCoy's 5A medium (Welgene, Inc., Gyeongsan, South Korea) supplemented with $10 \%$ fetal bovine serum (Gibco; Thermo Fisher Scientific, Inc.) and $1 \%$ penicillin/streptomycin at $37^{\circ} \mathrm{C}$ in a humidified atmosphere of $5 \% \mathrm{CO}_{2}$. The pan-caspase inhibitor Z-VAD-FMK was purchased from Sigma-Aldrich (Merck KGaA, Darmstadt, Germany). Inhibition of Fas and death receptor 5 (DR5) was performed using the small interfering RNA (siRNA). To transfect siRNA, SW480 and HCT116 cells were seeded into 6-well plates at a density of $3 \times 10^{5}$ cells/well at $37^{\circ} \mathrm{C}$ such that they would be $40-50 \%$ confluent at the time of transfection. On the next day, $20 \mu \mathrm{M}$ siRNA was transfected with $5 \mu \mathrm{l}$ Lipofectamine ${ }^{\circledR}$ RNAiMAX reagent (Invitrogen; Thermo Fisher Scientific, Inc.), according to the manufacturer's protocols. Further experiments were performed $24 \mathrm{~h}$ post transfection. Fas and DR5 siRNA were purchased from Santa Cruz Biotechnology, Inc. (Dallas, TX, USA). Scrambled siRNA (AllStars Negative Control siRNA; Qiagen GmbH, Hilden, Germany) was used as a negative control. Reversine was purchased from Cayman Chemical (Ann Arbor, MI, USA).

Cell proliferation assay. SW480 and HCT116 cells were seeded onto a 96-well plate at a density of $1 \times 10^{4}$ cells/well and were incubated for $24 \mathrm{~h}$ at $37^{\circ} \mathrm{C}$. Cells were then treated with different concentrations of reversine $(0,0.5,1,5,10$, and $20 \mu \mathrm{M})$ with dimethyl sulfoxide (Sigma-Aldrich; Merck KGaA) for 24 and $48 \mathrm{~h}$ at $37^{\circ} \mathrm{C}$. Subsequently, the cells were treated with WST-1 reagent (EZ-CYTOX; DoGen; Daeillab, Seoul, Korea) for $1 \mathrm{~h}$ at $37^{\circ} \mathrm{C}$. After the treatment, absorbance at $450 \mathrm{~nm}$ was measured using a microplate reader (Infinite M200; Tecan Group Ltd., Mannedorf, Switzerland). Each experiment was conducted in triplicate wells and was repeated at least three times.

Calcein-acetomethoxy (AM) staining. SW480 and HCT116 cells were seeded onto a 96-well plate at a density of $1 \times 10^{4}$ cells/well and incubated for $24 \mathrm{~h}$ at $37^{\circ} \mathrm{C}$. Cells were then treated with different concentrations of reversine $(0,0.5$, $1,5,10$ and $20 \mu \mathrm{M}$ ) with dimethyl sulfoxide (Sigma-Aldrich; Merck KGaA) for 24 at $37^{\circ} \mathrm{C}$. After the reversine treatment, cells were stained with $1 \mu \mathrm{M}$ Calcein-AM solution (Invitrogen; Thermo Fisher Scientific, Inc.) for $60 \mathrm{~min}$ at $37^{\circ} \mathrm{C}$. The cells were observed and imaged using a fluorescence microscope (x200; DMI 3000B; Leica Microsystems GmbH, Wetzlar, Germany).

Flow cytometric analysis. SW480 and HCT116 cells were seeded in a 6 -well plate at a density of $5 \times 10^{5}$ cells/well and were incubated for $24 \mathrm{~h}$ at $37^{\circ} \mathrm{C}$ prior to treatment with reversine. Subsequently, the cells were treated with reversine $(0,1,5$ and $10 \mu \mathrm{M}$ ) for 24 at $37^{\circ} \mathrm{C}$, and were resuspended in $100 \mu \mathrm{l}$ of $1 \mathrm{X}$ binding buffer (BD Biosciences, San Jose, CA, USA). These cells were incubated with 7-amino-actinomycin D and Annexin V-APC (BD Biosciences) for $20 \mathrm{~min}$ at room temperature. To analyze the number of apoptotic cells, a FACSCalibur flow cytometer (Becton-Dickinson and Company, Franklin Lakes, NJ, USA) and WinMDI version 2.9 (The Scripps Research Institute, San Diego, CA, USA) were used.

Cell cycle analysis. SW480 and HCT116 cells were seeded in a 6-well plate at a density of $5 \times 10^{5}$ cells/well and were incubated for $24 \mathrm{~h}$ at $37^{\circ} \mathrm{C}$. Subsequently, the cells were treated with reversine $(0$ and $1 \mu \mathrm{M})$ for $24 \mathrm{~h}$ at $37^{\circ} \mathrm{C}$, and were fixed with $70 \%$ ethanol for $1 \mathrm{~h}$ at $-20^{\circ} \mathrm{C}$. These cells were resuspended in $100 \mu \mathrm{l}$ of $1 \mathrm{U} / \mathrm{ml}$ RNase A (DNase free) for $20 \mathrm{~min}$ at room temperature and incubated with $10 \mu \mathrm{g} / \mathrm{ml}$ of propidium iodide (both from Sigma-Aldrich; Merck KGaA) for 30 min at room temperature. To analyze the proportions of cell cycle, a FACSCalibur flow cytometer and WinMDI version 2.9 were used.

DNA fragmentation. Reversine-treated cells were incubated with cell lysate buffer (1\% NP-40 in $20 \mathrm{mM}$ EDTA, and $50 \mathrm{mM}$ Tris-HCl; $\mathrm{pH}$ 7.5) for $30 \mathrm{~min}$ on ice. The samples were then centrifuged at $12,000 \times \mathrm{g}$ for $30 \mathrm{~min}$ at $4^{\circ} \mathrm{C}$. RNase A was added to the supernatant and incubated for $2 \mathrm{~h}$ at $56^{\circ} \mathrm{C}$. Proteinase $\mathrm{K}$ was added to the supernatant and the mixture was incubated for $2 \mathrm{~h}$ at $37^{\circ} \mathrm{C}$. An equal volume of isopropanol was added and the mixture was incubated at $-80^{\circ} \mathrm{C}$ overnight to precipitate the genomic DNA. The genomic DNA was loaded onto $2 \%$ agarose gel and was stained with $0.1 \%$ ethidium bromide for $10 \mathrm{~min}$ at $37^{\circ} \mathrm{C}$. The DNA was visualized under ultraviolet light transilluminator.

Western blotting. Reversine-treated cells were lysed in Radioimmunoprecipitation Assay extraction solution with Halt $^{\mathrm{TM}}$ Phosphatase inhibitor and Halt ${ }^{\mathrm{TM}}$ Protease inhibitor cocktails (Thermo Fisher Scientific, Inc.) for $30 \mathrm{~min}$ on ice. The protein concentration was measured using a Bicinchoninic Acid protein assay (Thermo Fisher Scientific, Inc.). Equal amounts of $20 \mu \mathrm{g}$ proteins were separated using $10 \%$ SDS-PAGE and transferred to a polyvinylidene fluoride membrane (Bio-Rad Laboratories, Inc., Hercules, CA, USA). The membranes was blocked with $5 \%$ bovine serum albumin (Sigma-Aldrich; Merck KGaA) for $1 \mathrm{~h}$ at room temperature and then incubated overnight at $4^{\circ} \mathrm{C}$ with primary antibodies at 1:1,000 dilution. Primary antibodies against the following proteins were used: Cleaved poly(ADP-ribose) polymerase (PARP; cat. no. 5625), cleaved caspase-3 (cat. no. 9664), cleaved caspase-7 (cat. no. 8438), cleaved caspase-8 (cat. no. 9746), second mitochondria-derived activator of caspase/direct inhibitor of apoptosis-binding protein with low pI (SMAC/DIABLO; cat. no. 2954), B-cell lymphoma-extra large (Bcl-xL; cat. no. 2764), Fas (cat. no. 4233), DR5 (cat. no. 8074), p21 (cat. no. 2947), p27 (cat. no. 2552) and p57 (cat. no. 2557) (Cell Signaling Technology, Inc., Danvers, MA, USA), and GAPDH (cat. no. FL-335; Santa Cruz Biotechnology, Inc.). The membranes were washed four time with TBS-0.1\% Tween-20 and were incubated with a horseradish peroxidase (HRP)-conjugated secondary antibody at 1:2,000 dilution for $1 \mathrm{~h}$ at room temperature. The HRP-conjugated anti-rabbit (cat. no. 7074) and anti-mouse 


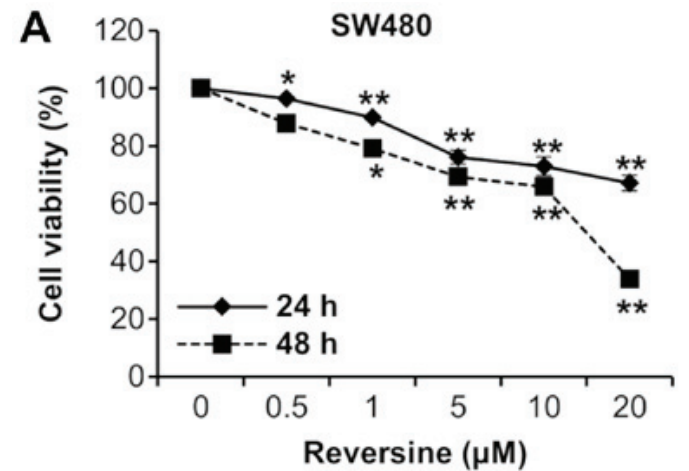

B Reversine $(\mu \mathrm{M})$

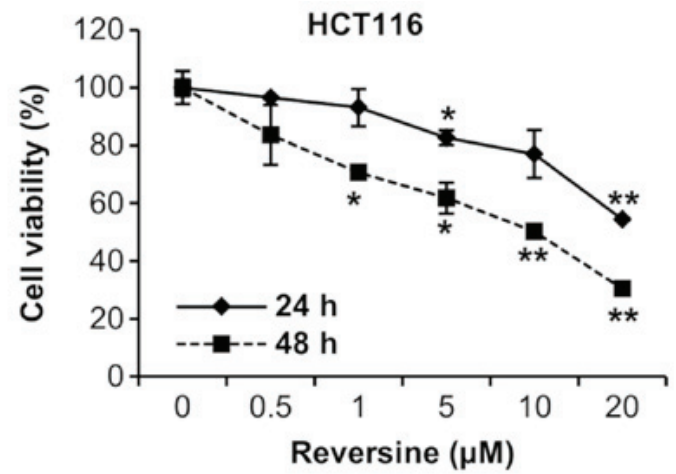

10

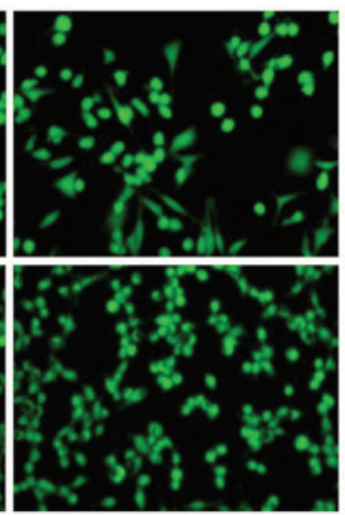

20

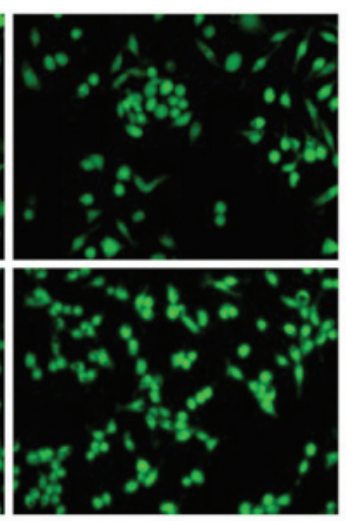

Figure 1. Reversine inhibits the growth of human colorectal cancer cells. (A) Human colorectal cancer cell lines SW480 and HCT116 were either exposed to 0-20 $\mu \mathrm{M}$ reversine for 24 and $48 \mathrm{~h}$, or left untreated. Thereafter, cell viability was measured with a WST-1 assay. (B) SW480 and HCT116 cells were treated with the indicated concentrations of reversine for $24 \mathrm{~h}$. Cell morphology was observed under a fluorescence microscope following Calcein-acetomethoxy solution staining. ( $\mathrm{P}<0.05$ and ${ }^{* *} \mathrm{P}<0.01$ vs. control).

(cat. no. 7076) secondary antibodies were purchased from Cell Signaling Technology, Inc. Protein bands were developed using an Enhanced Chemiluminescent reagent (GE Healthcare Life Sciences, Little Chalfont, UK) and the luminescent image analyzer LAS-4000 (Fujifilm, Tokyo, Japan) was used to analyze the bands.

Statistical analysis. The results are presented as the mean \pm standard deviation. Differences between groups were determined by Student's t-test. The statistical software program used was SPSS (Version 18.0; SPSS, Inc., Chicago, IL, USA). P $<0.05$ was considered to indicate a statistically significant difference.

\section{Results}

Reversine inhibits the growth of human colorectal cancer cells. Firstly, the effects of reversine on the growth of the human colorectal cancer cell lines SW480 and HCT116 were investigated. The human colorectal cancer cells were exposed to different concentrations of reversine $(0-20 \mu \mathrm{M})$ for 24 and $48 \mathrm{~h}$. The effects of reversine against the cells were determined with a cell proliferation assay, followed by observation under inverted microscopy. The cell proliferation assays and inverted microscopy demonstrated that reversine treatment significantly inhibited cell growth of SW480 and HCT116 cells, compared with the control cells $(\mathrm{P}<0.05)$ (Fig. $1 \mathrm{~A}$ and $\mathrm{B})$. These results indicated that reversine inhibits proliferation in human colorectal cancer cells.
Reversine induces apoptosis and cell cycle arrest in human colorectal cancer cells. In order to determine whether or not reversine induced apoptosis and cell cycle arrest in human colorectal cancer cells, flow cytometric analyses and a DNA fragmentation assay were performed. Human colorectal cancer cells were exposed to different concentrations of reversine $(0-20 \mu \mathrm{M})$ for $24 \mathrm{~h}$. Reversine treatment $(0.5-10 \mu \mathrm{M})$ induced an increase in DNA fragmentation in SW480 and HCT116 cells, compared with non-treated control (Fig. 2A). The proportion of early and late apoptotic cells within the group treated with reversine was increased, compared with the non-treated control, in SW480 and HCT116 cells (Fig.2B). To determine the activation of caspases, key enzymes of apoptosis, the caspase-specific activities were further investigated. The expression of cleaved PARP, caspase-3, -7 and -8 was upregulated in the SW480 and HCT116 cells following reversine treatment, in a dose-dependent manner (Fig. 2C). Additionally, whether reversine treatment resulted in modulation of apoptosis-regulatory proteins was further examined. As depicted in Fig. 2C, reversine treatment resulted in an increase in the levels of pro-apoptotic protein SMAC/DIABLO in SW480 and HCT116 cells, but the levels of the anti-apoptotic protein $\mathrm{Bcl}-\mathrm{xL}$ were not altered in response to reversine treatment. In addition, the effect of reversine on death receptor signaling pathways was investigated, and it was observed that the expression of DR5 and Fas proteins was upregulated by reversine treatment in SW480 and HCT116 cells (Fig. 2C). Reversine treatment resulted in cell cycle arrest in the subG1 and G2/M phase of SW480 and HCT116 
A

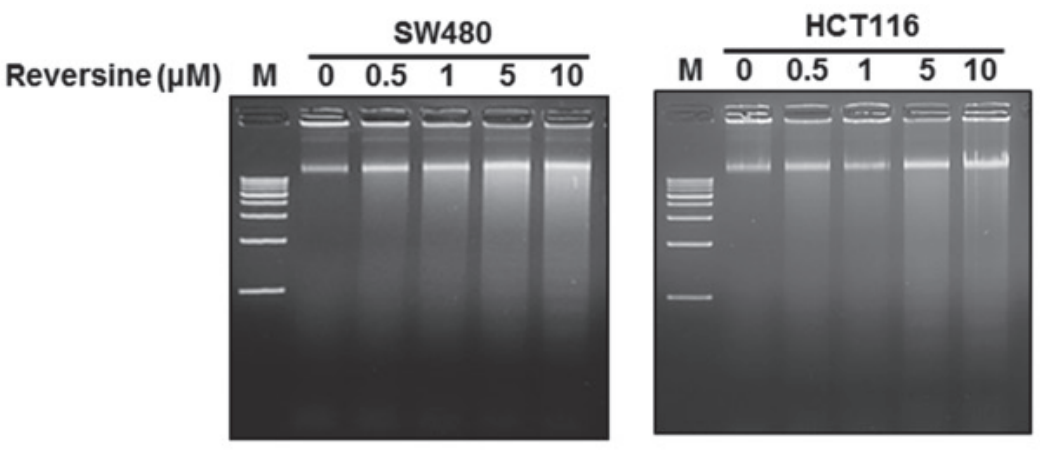

B

Reversine $(\mu \mathrm{M})$
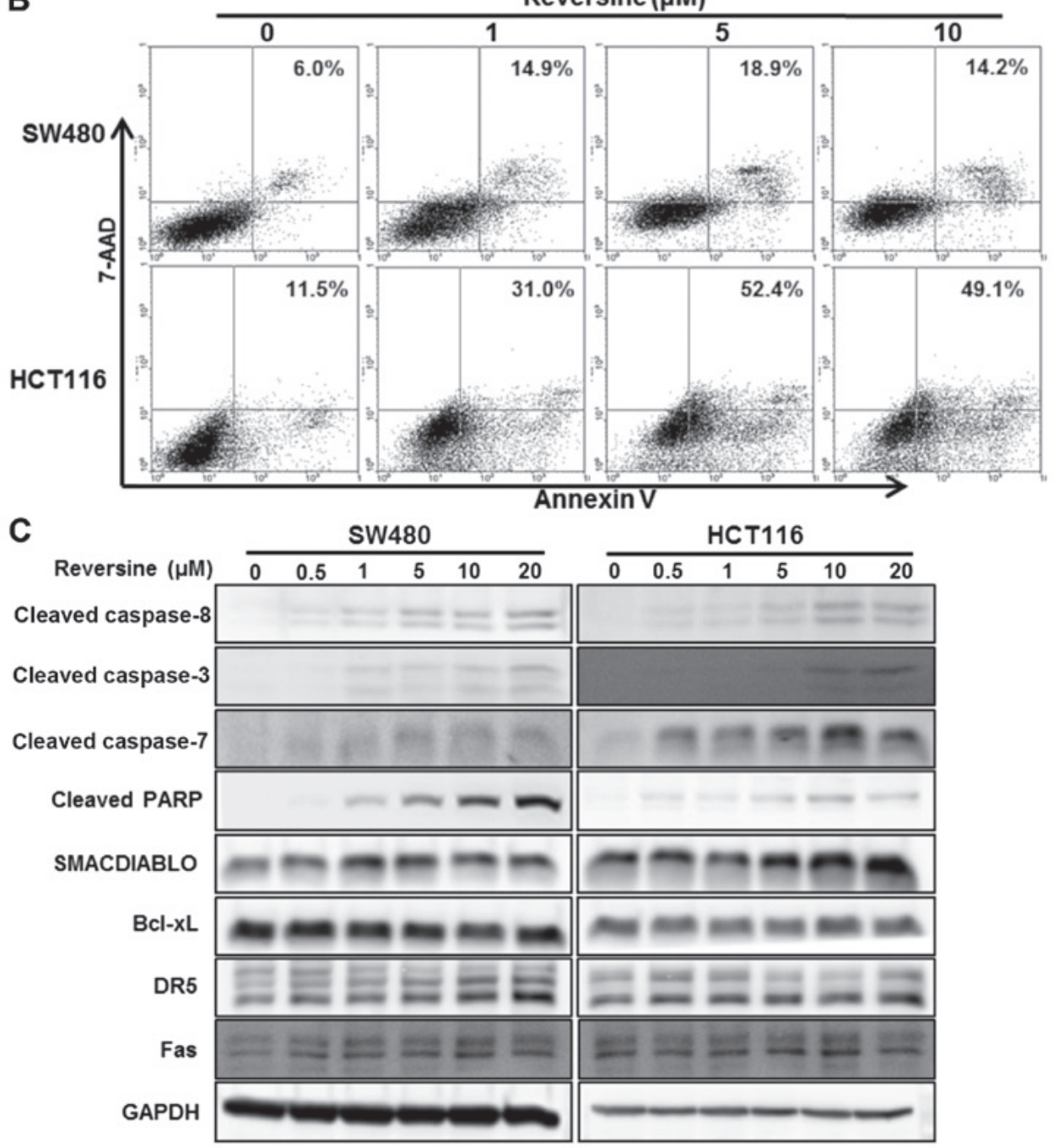

Figure 2. Reversine induces apoptosis in human colorectal cancer cells. SW480 and HCT116 cells were exposed to different concentrations of reversine for 24 h. (A) Apoptotic DNA fragmentation was analyzed by agarose gel electrophoresis. (B) Treated cells were stained with Annexin V and the number of apoptotic cells was evaluated. (C) Protein levels were detected by western blotting. GAPDH was used as a loading control. Cas, caspase; PARP, poly(ADP-ribose) polymerase; SMAC/DIABLO, second mitochondria-derived activator of caspase/direct inhibitor of apoptosis-binding protein with low pI; DR5, death receptor 5; 7-AAD, 7-amino-actinomycin D.

cells (Fig. 3A). Subsequently, the effects of reversine treatment on various CDK inhibitors (CDKIs) involved in cell cycle arrest in human colorectal cancer cells were evaluated. The p21, p27 and p57 protein levels were notably increased by reversine treatment in SW480 and HCT116 cells (Fig. 3B). Cyclins and CDKs were negatively regulated by CDKIs. Additionally, we examined the effects of reversine on the expression levels of cyclin D1 and CDK2. The cyclin D1 protein level was notably decreased by reversine treatment in SW480 and HCT116 cells.
The CDK2 protein level was notably decreased in SW480 cells but was not altered in response to reversine treatment in HCT116 cells (Fig. 3B).

Pan-caspase inhibitor attenuates the reversine-induced inhibition of cell growth and induction of apoptosis in human colorectal cancer cells. The pan-caspase inhibitor Z-VAD-FMK $(20 \mu \mathrm{M})$ was used to determine whether cell growth was inhibited and apoptosis was induced by reversine 
A

Reversine $(\mu \mathrm{M})$
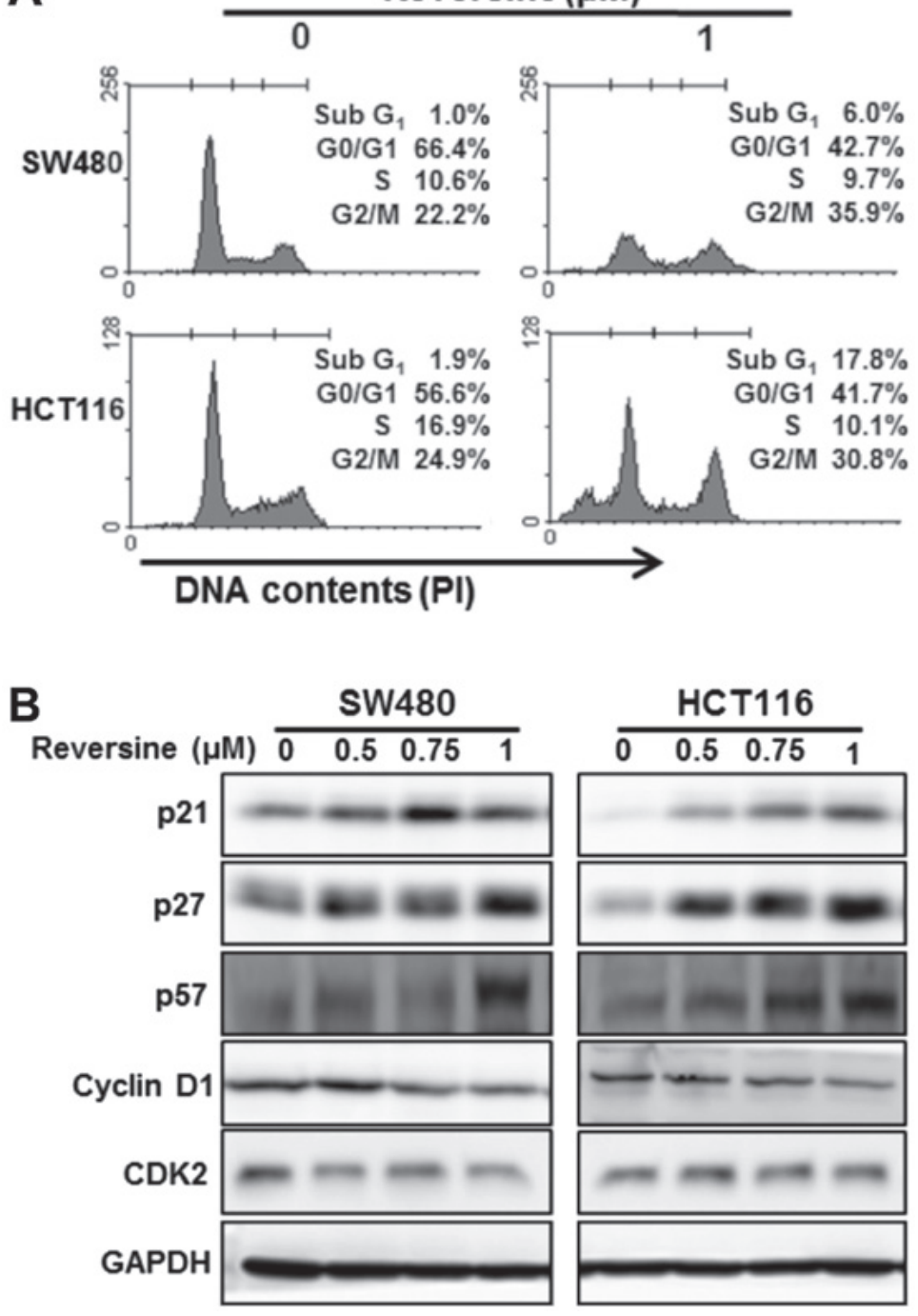

Figure 3. Reversine induces cell cycle arrest in human colorectal cancer cells. SW480 and HCT116 cells were treated with the indicated concentrations of reversine for $24 \mathrm{~h}$. (A) Treated cells were stained with PI and subjected to flow cytometric analysis to determine the cell distribution at each phase of cell cycle. (B) Cells treated with reversine were lysed for western blotting analysis with antibodies against various proteins involved in cell cycle arrest, including the CDK inhibitors p21, p27 and p57, cyclin D1 and CDK2. GAPDH was used as a loading control. CDK, cyclin-dependent kinase; PI, propidium iodide.

treatment. The inhibition of cell growth by reversine treatment was reversed in SW480 and HCT116 cells by Z-VAD-FMK treatment (Fig. 4A). The increase in the number of early and late apoptotic cells by reversine treatment was also attenuated in SW480 and HCT116 cells by Z-VAD-FMK treatment (Fig. 4B). Furthermore, Z-VAD-FMK abrogated the reversine-induced PARP, and caspase- 3 and -8 activation. However, Z-VAD-FMK did not notably affect reversine-induced DR5 and Fas protein expression (Fig. 4C). Therefore, reversine treatment exerts inhibition of cell growth and promotion of apoptosis via direct activation of caspases in human colorectal cancer cells.

Impact of reversine on Fas and DR5 signaling pathways in human colorectal cancer cells. To confirm whether Fas and DR5 signaling pathways are directly upregulated by reversine treatment, SW480 and HCT116 cells were transfected with Fas and DR5 siRNAs for $24 \mathrm{~h}$, and then $5 \mu \mathrm{M}$ reversine was added. To determine whether activation of Fas and DR5 is associated with reversine-induced cell apoptosis, flow cytometry was conducted. The increase in the number of early and late apoptotic cells by reversine treatment was attenuated following inhibition of Fas and DR5 by siRNA in SW480 and HCT116 cells (Fig. 5A). Inhibition of Fas and DR5 by siRNA suppressed reversine-induced cell cycle arrest of the subG1 and G2/M phase (Fig. 5B). Inhibition of Fas and DR5 by siRNAs suppressed reversine-induced upregulation of the Fas and DR5 proteins. Reversine-induced caspase- 8 and -3 , and PARP activation was attenuated following inhibition of Fas and DR 5 by siRNA (Fig. 5C). These results indicated that reversine-induced apoptosis and cell cycle arrest in human colorectal cancer cells is mediated by activation of the Fas and DR5 signaling pathways.

\section{Discussion}

Reversine, asynthetic purineanalogue,induces dedifferentiation of murine myoblasts to multipotent progenitor cells, which can redifferentiate into other different cell types (3-6). Previously, reversine has been demonstrated to exert anticancer effects via induction of apoptosis, cell cycle arrest and autophagy in numerous human cancer types, including breast, lung and 
A
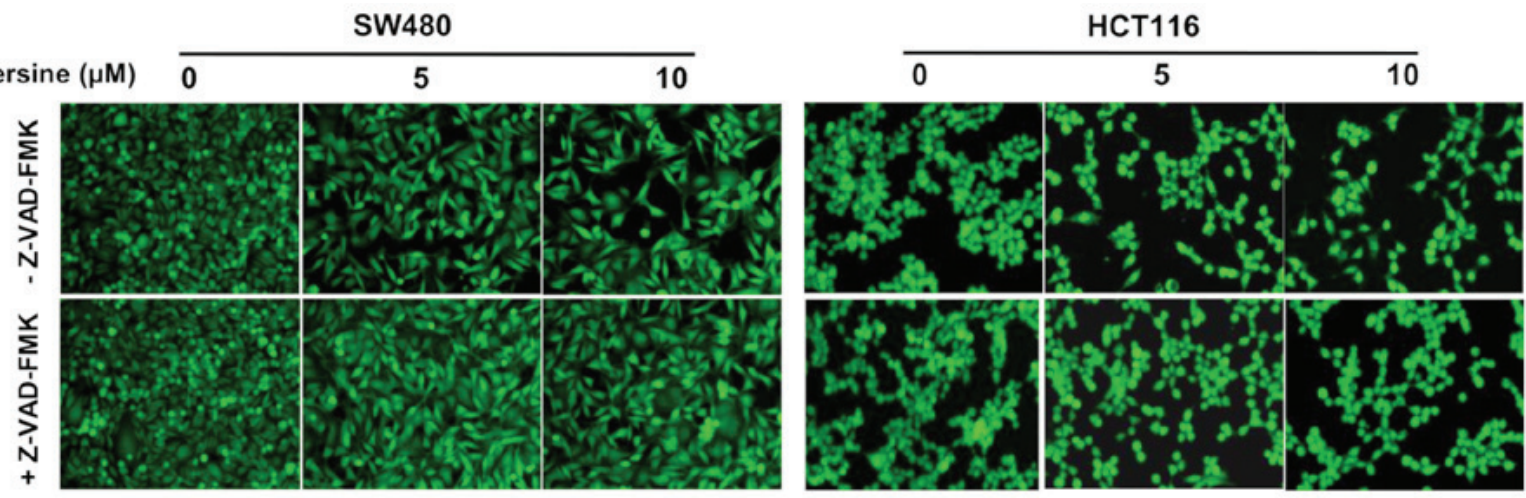

B
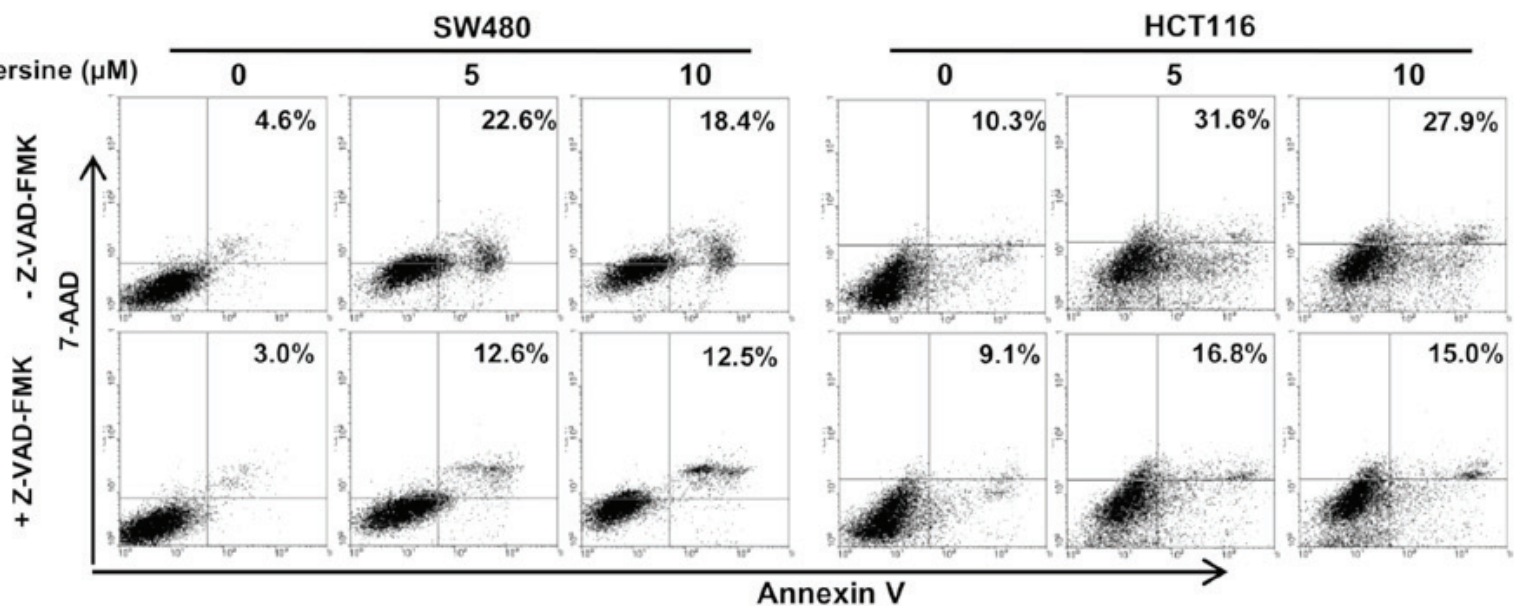

C
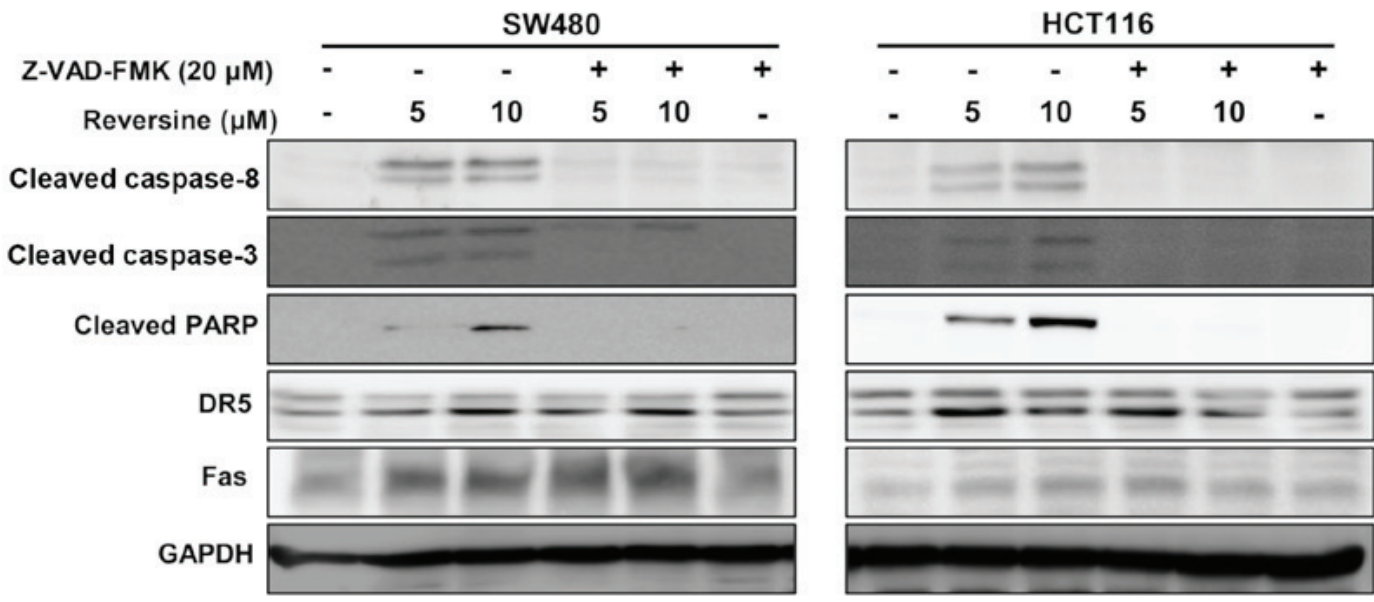

Figure 4. Pan-caspase inhibitor attenuates reversine-induced inhibition of cell growth and induction of apoptosis in human colorectal cancer cells. SW480 and HCT116 cells were pretreated with $20 \mu \mathrm{M}$ of the pan-caspase inhibitor Z-VAD-FMK for $2 \mathrm{~h}$ and then exposed to the indicated concentrations of reversine for 24 h. (A) Cell morphology was observed under a fluorescence microscope following Calcein-acetomethoxy solution staining. (B) Treated cells were stained with Annexin V and the number of apoptotic cells was counted. (C) Protein levels were detected by western blotting. GAPDH was used as a loading control. Cas, caspase; PARP, poly(ADP-ribose) polymerase; DR5, death receptor 5; 7-AAD, 7-amino-actinomycin D.

thyroid cancer (10-23). Thus, the impact of reversine on tumor cell behavior and its association with intracellular signaling pathways in human colorectal cancer cells were investigated.

Apoptosis is an essential mechanism for cell morphogenesis, cell turnover and removal of damaged cells. Balance between cell growth and apoptosis is crucial to ensure normal development and homeostasis (24-26). However, deregulation of cell growth and apoptosis is responsible for cancer development, progression and resistance to treatment (24-26). In the present study, reversine inhibited proliferation and induced apoptosis in human colorectal cancer cells. Recently, reversine was demonstrated to suppress the migration and invasion of human colorectal cancer RKO cells by inhibiting the c-Jun NH2-terminal kinase signaling pathway, which serves a crucial role in cell proliferation, cell cycle progression and apoptosis (21). These results indicated that reversine may contribute to altering the invasive and oncogenic phenotypes of human colorectal cancer cells.

Apoptosis involves the activation of caspases, which participate in enzymatic cascades that terminate in cellular 
A
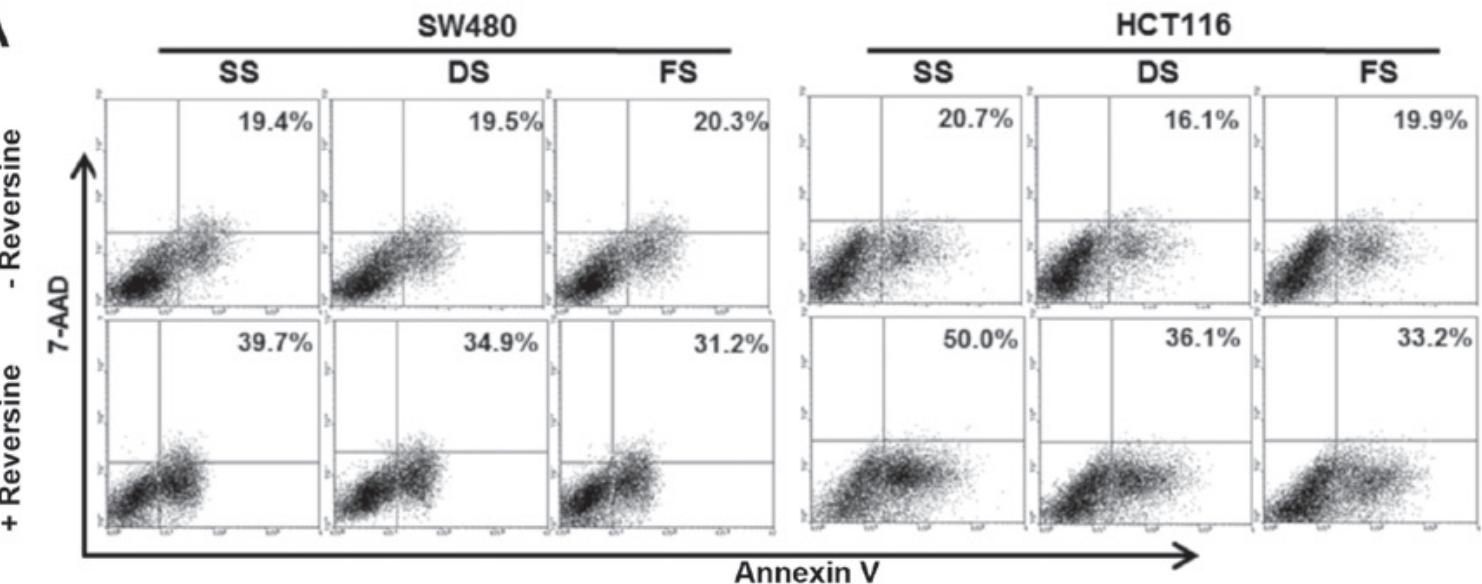

B

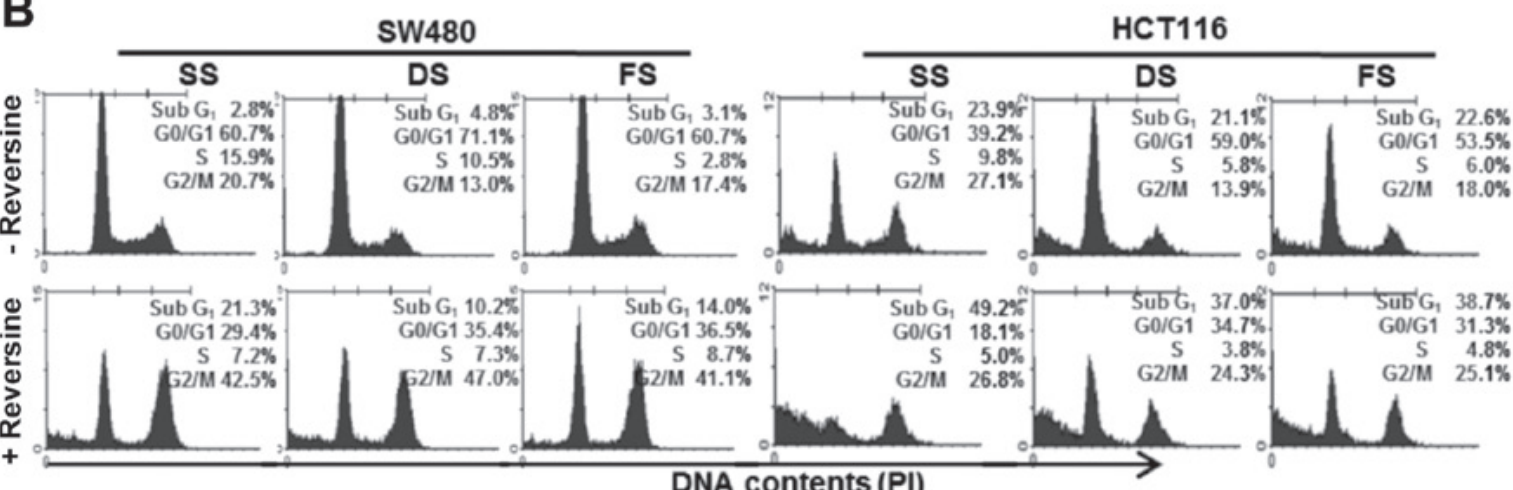

DNA contents (PI)

C

SW480
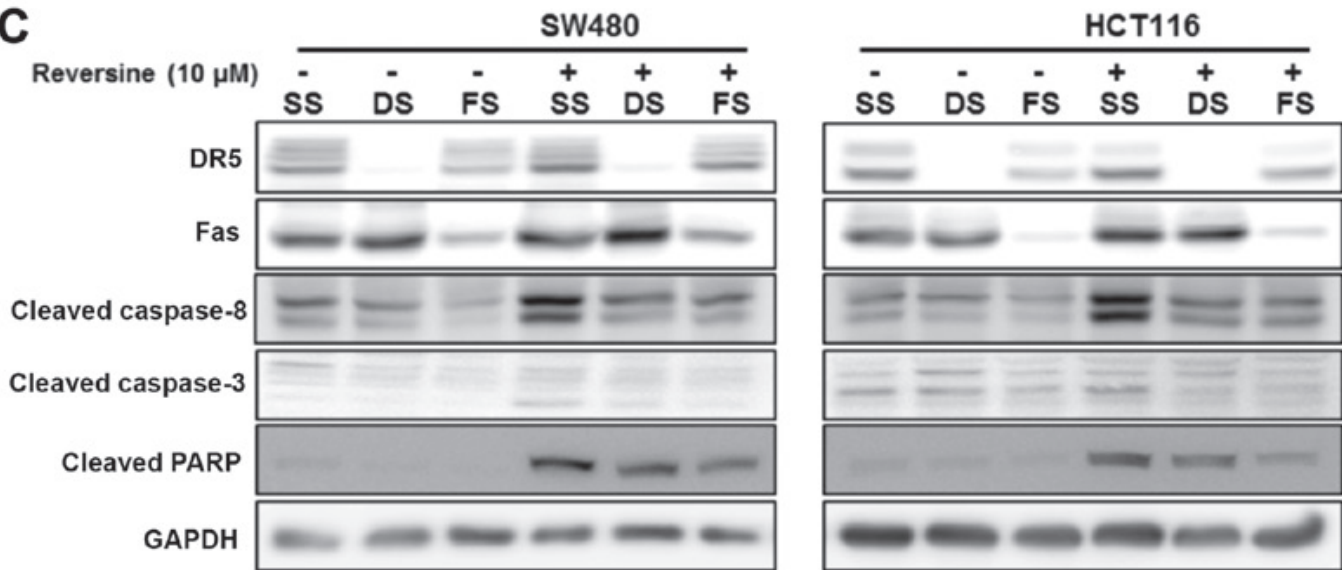

Figure 5. Impact of reversine on Fas and DR5 signaling pathways in human colorectal cancer cells. SW480 and HCT116 cells were transfected with Fas and DR5 siRNA for $24 \mathrm{~h}$ and then exposed to the indicated concentrations of reversine for $24 \mathrm{~h}$. (A) Treated cells were stained with Annexin V and the number of apoptotic cells was counted. (B) Treated cells were stained with PI and subjected to flow cytometric analysis to determine the cell distribution at each phase of cell cycle. (C) Protein levels were detected by western blotting. GAPDH was used as a loading control. siRNA, small interfering RNA; SS, scrambled siRNA, DS, death receptor 5 siRNA; FS, Fas siRNA; Cas, caspase; PARP, poly(ADP-ribose) polymerase; DR5, death receptor 5; PI, propidium iodide; 7-AAD, 7-amino-actinomycin D.

disassembly, and is a complex process that results from multiple genetic alterations in pro- and anti-apoptotic genes. Thus, the effects of reversine on apoptosis in human colorectal cancer cells were investigated. Reversine treatment induced apoptosis by activating PARP, and caspase- $3,-7$ and -8 , and enhancing the levels of the pro-apoptotic protein SMAC/DIABLO. Furthermore, the pan-caspase inhibitor was used to determine the association between reversine-induced apoptosis and caspase activation. The present study demonstrated that the pan-caspase inhibitor abrogated the reversine-induced increase in the number of early and late apoptotic cells, and caspase-3,
-8 and PARP activation. Therefore, reversine treatment induces apoptosis by directly inducing caspase activity in human colorectal cancer cells. These results were consistent with those of previous studies on other human cancer types (10-23).

Cell cycle, cell proliferation and cell apoptosis are associated with the circadian clock, which controls the rhythms of various physiological processes, including cell division, cell migration and metabolism $(27,28)$. The disruption of the circadian clock is associated with cancer development and progression $(27,28)$. Recently, reversine and reversine-associated molecules were indicated to cause cell cycle arrest in the $\mathrm{G} 2 / \mathrm{M}$ phase and 
polyploidy in the HCT116 colorectal cancer cell line (14). In the present study, reversine treatment induced cell cycle arrest at the subG1 and G2/M phases of human colorectal cancer cells.

The cell cycle progression is regulated by a complex system involving cyclins, CDKs and CDKIs. CDKs are serine/threonine kinases that are modulated by interaction with positive effectors, cyclins and negative regulators, CDKIs. Until now, two families of CDKIs have been identified: The Cip/Kip family; and the INK family (27-29). The Cip/Kip family includes p21, p27 and p57. The INK family includes p16, p15, p18 and p19 (27-29). In the present study, reversine treatment induced cell cycle arrest in the subG1 and G2/M phases via the upregulation of p21, p27 and p57, and the downregulation of cyclin D1. Previously, reversine induced cell growth arrest and polyploidy by upregulating p21, cyclin D3 and CDK6, while downregulating cyclin B1 and CDK1 (7). Among the numerous reported CDKIs, aberrant expression of p21, p27 and p57 has been demonstrated in various human cancer cells and their downregulation has been associated with tumor progression in various human cancer types, including pancreas, breast, lung and colorectal cancer, indicating their role as tumor suppressors (30-32). Therefore, reversine may contribute to inhibit colorectal cancer progression via cell cycle arrest by upregulation of members of the Cip/Kip family.

The Fas/FasL and DR5 signaling pathways are the major pathways that regulate apoptosis (33-35). DR5 is located on the surface of cancer cells, and stimulation of this death receptor activates the caspase-8-dependent apoptotic pathway (33-35). Fas-associated DR5 protein and caspase-8 are essential for anticancer agent-induced cell apoptosis in numerous human cancer types, including gastric and colorectal cancer (36-38). In the present study, the expression of Fas, DR5, caspase- 8 and -3, and PARP proteins was upregulated by reversine treatment in human colorectal cancer cells. Reversine-induced apoptosis and cell cycle arrest were inhibited by inhibition of Fas and DR5 via siRNA. These results indicated that reversine induced caspase-dependent apoptosis and cell cycle arrest by activation of the Fas and DR5 signaling pathways.

Overall, in the present study, reversine treatment suppressed tumor progression by inhibition of cell proliferation, induction of apoptosis and cell cycle arrest through upregulation of the Fas and DR5 signaling pathways in human colorectal cancer cells. The present study indicated that reversine may be used as a novel anticancer agent in human colorectal cancer.

\section{Acknowledgements}

Not applicable.

\section{Funding}

This study was supported by research funds from the Research Institute of Clinical Medicine, Chonnam National University Hwasun Hospital in 2017 (grant no. HCRI 17912-1), Republic of Korea, and partly the National Research Foundation of Korea grant (grant no. NRF-2017R1A2B4004703) funded by the Korean government (Ministry of Science, ICT and Future Planning), Republic of Korea.

\section{Availability of data and materials}

All data generated or analyzed during this study are included in this published article.

\section{Authors' contributions}

YEJ was involved in the conceptualization of the study. YLP, SYH, SYP, JHC, MWJ, DSM and HSK were involved in data curation, were responsible for formal analysis and provided resources. YLP, SYH and YEJ were involved in the investigative part of the study, were involved in the methodology and were involved in the writing, reviewing and editing of the manuscript. YEJ was involved in project administration, and was involved in the writing of the manuscript and original draft preparation.

\section{Ethics approval and consent to participate}

Not applicable.

\section{Patient consent for publication}

Not applicable.

\section{Competing interests}

The authors declare that they have no competing interests.

\section{References}

1. Brenner H, Kloor M and Pox CP: Colorectal cancer. Lancet 383: 1490-1502, 2014

2. Choi Y, Sateia HF, Peairs KS and Stewart RW: Screening for colorectal cancer. Semin Oncol 44: 34-44, 2017.

3. Chen S, Zhang Q, Wu X, Schultz PG and Ding S: Dedifferentiation of lineage-committed cells by a small molecule. J Am Chem Soc 126: 410-411, 2004.

4. Chen S, Takanashi S, Zhang Q, Xiong W, Zhu S, Peters EC, Ding S and Schultz PG: Reversine increases the plasticity of lineage-committed mammalian cells. Proc Natl Acad Sci USA 104: 10482-10487, 2007.

5. Lee EK, Bae GU, You JS, Lee JC, Jeon YJ, Park JW, Park JH, Ahn SH, Kim YK, Choi WS, et al: Reversine increases the plasticity of lineage-committed cells toward neuroectodermal lineage. J Biol Chem 284: 2891-2901, 2009.

6. Pikir BS, Susilowati H, Hendrianto E and Abdulrantam F: Reversin increase the plasticity of bone marrow-derived mesenchymal stem cell for generation of cardiomyocyte in vitro. Acta Med Indones 44: 23-27, 2012.

7. Yan M, Wang C, He B, Yang M, Tong M, Long Z, Liu B, Peng F, $\mathrm{Xu}$ L, Zhang Y, et al: Aurora-A Kinase: A Potent Oncogene and Target for Cancer Therapy. Med Res Rev 36: 1036-1079, 2016.

8. Tang A, Gao K, Chu L, Zhang R, Yang J and Zheng J: Aurora kinases: Novel therapy targets in cancers. Oncotarget 8: 23937-23954, 2017.

9. Malumbres M and Pérez de Castro I: Aurora kinase A inhibitors: Promising agents in antitumoral therapy. Expert Opin Ther Targets 18: 1377-1393, 2014.

10. Hsieh TC, Traganos F, Darzynkiewicz Z and Wu JM: The 2,6-disubstituted purine reversine induces growth arrest and polyploidy in human cancer cells. Int J Oncol 31: 1293-1300, 2007.

11. Lu CH, Liu YW, Hua SC, Yu HI, Chang YP and Lee YR: Autophagy induction of reversine on human follicular thyroid cancer cells. Biomed Pharmacother 66: 642-647, 2012.

12. Piccoli M, Palazzolo G, Conforti E, Lamorte G, Papini N, Creo P, Fania C, Scaringi R, Bergante S, Tringali C, et al: The synthetic purine reversine selectively induces cell death of cancer cells. J Cell Biochem 113: 3207-3217, 2012. 
13. Kuo CH, Lu YC, Tseng YS, Shi CS, Chen SH, Chen PT, Wu FL, Chang YP and Lee YR: Reversine induces cell cycle arrest, polyploidy, and apoptosis in human breast cancer cells. Breast Cancer 21: 358-369, 2014

14. Bosco B, Defant A, Messina A, Incitti T, Sighel D, Bozza A, Ciribilli Y, Inga A, Casarosa S and Mancini I: Synthesis of 2,6-diamino-substituted purine derivatives and evaluation of cel cycle arrest in breast and colorectal cancer cells. Molecules 23 : E1996, 2018.

15. Cheng L, Wang H, Guo K, Wang Z, Zhang Z, Shen C, Chen L and Lin J: Reversine, a substituted purine, exerts an inhibitive effect on human renal carcinoma cells via induction of cell apoptosis and polyploidy. OncoTargets Ther 11: 1025-1035, 2018.

16. Qin HX, Yang J, Cui HK, Li SP, Zhang W, Ding XL and Xia YH: Synergistic antitumor activity of reversine combined with aspirin in cervical carcinoma in vitro and in vivo. Cytotechnology 65: 643-653, 2013

17. Rodrigues Alves AP, Machado-Neto JA, Scheucher PS, Paiva HH, Simões BP, Rego EM and Traina F: Reversine triggers mitotic catastrophe and apoptosis in K562 cells. Leuk Res 48: 26-31, 2016.

18. Lu YC, Lee YR, Liao JD, Lin CY, Chen YY, Chen PT and Tseng YS: Reversine induced multinucleated cells, cell apoptosis and autophagy in human non-small cell lung cancer cells. PLoS One 11: e0158587, 2016.

19. Lee YR, Wu WC, Ji WT, Chen JY, Cheng YP, Chiang MK and Chen HR: Reversine suppresses oral squamous cell carcinoma via cell cycle arrest and concomitantly apoptosis and autophagy. J Biomed Sci 19: 9, 2012.

20. D'Alise AM, Amabile G, Iovino M, Di Giorgio FP, Bartiromo M, Sessa F, Villa F, Musacchio A and Cortese R: Reversine, a novel Aurora kinases inhibitor, inhibits colony formation of human acute myeloid leukemia cells. Mol Cancer Ther 7: 1140-1149, 2008.

21. Jemaà M, Abassi Y, Kifagi C, Fezai M, Daams R, Lang F and Massoumi R: Reversine inhibits Colon Carcinoma Cell Migration by Targeting JNK1. Sci Rep 8: 11821, 2018.

22. Hua SC, Chang TC, Chen HR, Lu CH, Liu YW, Chen SH, Yu HI, Chang YP and Lee YR: Reversine, a 2,6-disubstituted purine, as an anti-cancer agent in differentiated and undifferentiated thyroid cancer cells. Pharm Res 29: 1990-2005, 2012

23. Bijian K, Lougheed C, Su J, Xu B, Yu H, Wu JH, Riccio K and Alaoui-Jamali MA: Targeting focal adhesion turnover in invasive breast cancer cells by the purine derivative reversine. $\mathrm{Br}$ J Cancer 109: 2810-2818, 2013.

24. Kiechle FL and Zhang X: Apoptosis: Biochemical aspects and clinical implications. Clin Chim Acta 326: 27-45, 2002.
25. Schultz DR and Harrington WJ Jr: Apoptosis: Programmed cell death at a molecular level. Semin Arthritis Rheum 32: 345-369, 2003.

26. Llambi F and Green DR: Apoptosis and oncogenesis: Give and take in the BCL-2 family. Curr Opin Genet Dev 21: 12-20, 2011

27. Lim S and Kaldis P: Cdks, cyclins and CKIs: Roles beyond cell cycle regulation. Development 140: 3079-3093, 2013.

28. Soták M,Sumová A and Pácha J: Cross-talk between the circadian clock and the cell cycle in cancer. Ann Med 46: 221-232, 2014.

29. Bonelli P, Tuccillo FM, Borrelli A, Schiattarella A and Buonaguro FM: CDK/CCN and CDKI alterations for cancer prognosis and therapeutic predictivity. BioMed Res Int 2014: 361020, 2014.

30. Wang K, Baldwin GS, Nikfarjam $\mathrm{M}$ and $\mathrm{He} \mathrm{H}$ : p21-activated kinase signalling in pancreatic cancer: New insights into tumour biology and immune modulation. World J Gastroenterol 24: 3709-3723, 2018.

31. Bencivenga D, Caldarelli I, Stampone E, Mancini FP, Balestrieri ML, Della Ragione F and Borriello A: p27Kip1 and human cancers: A reappraisal of a still enigmatic protein. Cancer Lett 403: 354-365, 2017.

32. Kobatake T, Yano M, Toyooka S, Tsukuda K, Dote H, Kikuchi T, Toyota M, Ouchida M, Aoe M, Date H, et al: Aberrant methylation of p57KIP2 gene in lung and breast cancers and malignant mesotheliomas. Oncol Rep 12: 1087-1092, 2004.

33. Villa-Morales $\mathrm{M}$ and Fernández-Piqueras J: Targeting the Fas/FasL signaling pathway in cancer therapy. Expert Opin Ther Targets 16: 85-101, 2012.

34. Mocellin S: Targeting death receptors to fight cancer: From biological rational to clinical implementation. Curr Med Chem 17: 2713-2728, 2010

35. Tschumi BO, Dumauthioz N, Marti B, Zhang L, Schneider P, Mach JP, Romero P and Donda A: CART cells are prone to Fasand DR5-mediated cell death. J Immunother Cancer 6: 71, 2018.

36. Wang X, Xue Q, Wu L, Wang B and Liang H: Dasatinib promotes TRAIL-mediated apoptosis by upregulating CHOP-dependent death receptor 5 in gastric cancer. FEBS Open Bio 8: 732-742, 2018.

37. Shlyakhtina Y, Pavet V and Gronemeyer H: Dual role of DR5 in death and survival signaling leads to TRAIL resistance in cancer cells. Cell Death Dis 8: e3025, 2017.

38. Karbasi A, Borhani N, Daliri K, Kazemi B and Manoochehri M: Downregulation of external death receptor genes FAS and DR5 in colorectal cancer samples positive for human papillomavirus infection. Pathol Res Pract 211: 444-448, 2015. 